\title{
Critical issues in the assessment of disability in schizophrenia
}

Margaret M. McClure

Fairfield University, mmcclure@fairfield.edu

Philip Harvey

Follow this and additional works at: https://digitalcommons.fairfield.edu/psychology-facultypubs Copyright 2007 Walsh Medical Media

The final publisher PDF has been archived here with permission from the copyright holder.

\section{Peer Reviewed}

\section{Repository Citation}

McClure, Margaret M. and Harvey, Philip, "Critical issues in the assessment of disability in schizophrenia" (2007). Psychology Faculty Publications. 22.

https://digitalcommons.fairfield.edu/psychology-facultypubs/22

\section{Published Citation}

McClure, M. M. \& Harvey, P. D. (2007). Critical issues in the assessment of disability in schizophrenia. Clinical Schizophrenia \& Related Psychoses, vol.1, no.2, 147-153.

This item has been accepted for inclusion in DigitalCommons@Fairfield by an authorized administrator of DigitalCommons@Fairfield. It is brought to you by DigitalCommons@Fairfield with permission from the rightsholder(s) and is protected by copyright and/or related rights. You are free to use this item in any way that is permitted by the copyright and related rights legislation that applies to your use. For other uses, you need to obtain permission from the rights-holder(s) directly, unless additional rights are indicated by a Creative Commons license in the record and/or on the work itself. For more information, please contact digitalcommons@fairfield.edu. 


\title{
Critical Issues in the Assessment of Disability in Schizophrenia
}

\author{
Margaret M. McClure, ${ }^{1,2}$ Philip D. Harvey 1,2
}

\section{Abstract}

Individuals with schizophrenia exhibit functional disability across a wide array of domains. These patients experience impairments in their social competence, vocational aptitude, everyday living skills, and self-care abilities, which in the majority of patients are severe enough to prevent the return to independent living, even after hallmark symptoms such as hallucinations and delusions are remitted. Unfortunately, assessment of the magnitude of disability in individual patients is hindered by several factors, such as reduced capability in the area of self-evaluation and inaccuracies in self-report, as well as the presence of potential contributing variables such as depression and poor self-esteem. Furthermore, additional barriers to recovery exist, such as fear of losing disability payments and factors such as discrimination. Performance-based measures of functioning are new and promising instruments for assessing the competencies of patients and address many of the problems with other methods of assessing disability. These measures could greatly aid clinicians in understanding the schizophrenia disease and recovery process, expanding treatment goals beyond the currently targeted positive and negative symptoms.

Key Words: Schizophrenia, Disability, Functional Outcome, Recovery,

Performance-Based Assessments

\section{Introduction}

Individuals with schizophrenia frequently achieve remission of hallmark symptoms of psychosis. However, few achieve true recovery. Instead, individuals with schizophrenia experience chronic disability in many domains of functioning, such as social competence, vocational achievement, everyday living skills, and self-care. In the current paper, we review domains of disability in schizophrenia, as well as methods for assessing individual disability.

${ }^{1} M$ t. Sinai School of Medicine, New York, NY 2VA VISN3 MIRECC, Bronx, NY

Address for correspondence: Margaret McNamara McClure, PhD, VA VISN3 MIRECC, OOMH,

130 West Kingsbridge Road, Bronx, NY 10468

Phone: 718-594-9000, x3844; Fax: 718-364-3576;

E-mail:Margaret.McNamara@mssm.edu

Submitted: June 8, 2007; Revised: June 14, 2007;

Accepted: June 16, 2007

\section{Functional Disability as the Core of Schizophrenia}

Over the last decade, the World Health Organization has changed its perspective on evaluating disability from focusing on the rate of mortality caused by the disease to other factors reflecting morbidity of illness, such as reduced quality of life and impaired engagement in activities. This shift has underscored the chronic burden schizophrenia creates for patients, caregivers, and society. The direct cost of treating schizophrenia has risen from $\$ 44$ billion (1) to $\$ 62.7$ billion (2) over the last decade. The indirect cost of the disability associated with schizophrenia is approximately another $\$ 32$ billion (2). The social and emotional costs of the illness are more difficult to quantify, particularly with an economic model. In fact, schizophrenia has been characterized as the most disabling of all mental illnesses (3). Unfortunately, although pharmacological advances have been effective at treating positive and negative symptoms of schizophrenia (4), the rate of true recovery from the illness, defined by a return to independent living, remains relatively 
unchanged from what it was a century ago (5). In addition, evidence has emerged suggesting that the functional disability of individuals with schizophrenia is in fact, a heritable trait. For example, Kendler et al. (6) found that among relatives of individuals with schizophrenia, the relative odds ratio of having occupational dysfunction $(\mathrm{OR}=3.4)$, compared to relatives of healthy individuals, was greater than the odds ratio for having positive schizotypy ( $\mathrm{OR}=1.93)$, a trait that is almost universally acknowledged to run in families of individuals with schizophrenia. Thus, functional disability within this population is not only severe, but it also appears to be heritable, suggesting that it is, in fact, a core aspect of the schizophrenia illness.

\section{Domains of Functional Disability in Schizophrenia}

The functional disability of schizophrenia is also pervasive and is present across a wide range of domains. Individuals with schizophrenia demonstrate impairments in their social outcomes, vocational achievement, everyday living skills, and self-care.

\section{Social Outcomes}

Individuals with schizophrenia exhibit severe deficits in their social functioning $(7,8)$. Individuals with schizophrenia are frequently isolated from others and have been found to have smaller social networks than control subjects $(9,10)$. When individuals with schizophrenia do communicate with others, they frequently have difficulty maintaining appropriate conversations and expressing their needs and feelings $(11,12)$. In addition, individuals with schizophrenia frequently fail to achieve major social milestones, such as getting married. For example, in one study of over 1,400 individuals with schizophrenia, only $12 \%$ were married (13). In fact, almost two-thirds of individuals with schizophrenia are unable to fulfill basic social roles such as spouse or parent (11).

\section{Vocational Achievement}

Rates of competitive employment for individuals with schizophrenia are estimated to be approximately 20\% (14), and, even with optimal support, employment rates for individuals with schizophrenia only rise to about $60 \%$ (15). In addition, although individuals with schizophrenia are frequently able to obtain employment while participating in supportive employment programs, many patients lose these jobs once the employment services cease (16). Many individuals with schizophrenia, in addition, received less education than would be expected given other demographic variables (10), which unfortunately may impede their abilities to gain employment during periods of symptoms remission (13).

\section{Everyday Living Skills}

Individuals with schizophrenia also experience problems completing tasks that require the use of everyday living skills, such as cooking, cleaning, money management, and using public transportation (17-20). Few individuals with schizophrenia are able to live independently. In fact, one large study of individuals with schizophrenia found that only $8 \%$ were living on their own and responsible for payment for their accommodations (21).

\section{Self-Care}

Individuals with schizophrenia experience many problems with self-care, most notably related to their poor medication adherence. Non-compliance for antipsychotic treatment in this population is estimated at approximately 50\% (22). In addition, individuals with schizophrenia rarely seek out preventative health care, even if it is available to them. For example, McCarthy et al. (23) found that for veterans with psychosis, distance to medical care facilities was a major barrier to receiving preventative treatment. While individuals with other serious mental illness overcame this obstacle by scheduling multiple appointments on the same day, individuals with schizophrenia did not. In addition, chronic patients appear to have worse self-care than less chronic patients (24).

\section{Methods for Assessing Functional Disabilities}

In the research literature, several domains have emerged for understanding the disability of individuals with schizophrenia. These include self-report, informant report, observational ratings, achievement of major milestones, and performance-based measures of functional skills. Although there are benefits to all of these, many also have drawbacks.

\section{Self-Report}

Self-report is the standard method of assessing patient progress in clinical settings as providers routinely ask patients about their progress. This method, which is also widely used in research settings, has several advantages. Patients frequently have sole access to some aspects of the information that is useful in assessing disability. In addition, patients are theoretically able to self-report subjective information that may be difficult for an outsider to determine, such as mood state and motivation.

Unfortunately, individuals with schizophrenia are notoriously poor informants as they frequently exhibit limited awareness of their psychotic symptoms (25). Furthermore, in one study correlations between individuals with schizophrenia self-reports about cognitive deficits and their neuropsychological performance were almost zero, while correlations between informants' ratings of cognitive deficits 
and patients' neuropsychological performance was much higher, $r=0.40$ (26). Additionally, case managers' ratings of functional outcomes were also more strongly correlated with performance-based measures of functional capacity than patients' self-ratings (27). In this study, patient's self-reports were consistently uncorrelated with case manager reports of everyday outcomes, such as employment and residential independence.

\section{Informant Report}

Informant reports have several advantages over selfreport. First, an informant report tends to be more objective than self-report. In addition, informants generally do not exhibit the same degree of lack of insight and cognitive impairments, such as problems with attention and memory, frequently found in individuals with schizophrenia (28). Finally, obtaining information from multiple informants could provide a broad view of the individual's functioning.

Informant reports, however, are not without their limitations. Many individuals with schizophrenia lack a close family member or friend who can serve as a reliable informant (29). Additionally, caregivers may not have access to all behavior that is important for assessing disability. Caregivers may also exhibit their own biases that prevent them from answering honestly or accurately. For example, caregivers may be afraid that if they provide positive ratings, patients may lose disability or medical benefits. Informants also may lack an objective understanding of what constitutes improvement or decline. For example, caregivers may not have enough training or knowledge of illness factors to provide valid assessments of functioning in domains such as social skills.

\section{Observational Ratings}

Observation ratings also have many important advantages. Trained observers are objective and skilled, and therefore are most likely to provide a valid description of behaviors of interest. Furthermore, observer ratings allow an objective comparison between patients. They also allow for the accurate assessment of changes within patients over time, as objective observers may identify subtle improvements not apparent to patients or caregivers.

Observational ratings also have their drawbacks, the first of which is their practicality. Behavior of interest may occur infrequently and, therefore, in observing a patient for a short amount of time one might miss it. In addition, observers can be very intrusive, and their presence can increase the social stigma already experienced by these patients.

\section{Assessing Major Milestones}

Tracking the successful attainment of major milestones achieved by individuals with schizophrenia is an important aspect of understanding disability. For example, it is very informative to know if individuals with schizophrenia marry, transition to independent living, or obtain a degree. Unfortunately, these milestones are rarely achieved by individuals with schizophrenia and thus lack practicality as a measurement tool to assess treatment progress. Further, these milestones require time and effort for achievement in the general population. It would be very unlikely that a shortterm follow-up study of achievement of these milestones in healthy individuals would find a high rate of change in a typical six-week study resembling a clinical treatment trial.

\section{Performance-Based Measures of Functional Skills}

Performance-based measures of functional skills are laboratory-based assessments during which participants are asked to actually perform everyday tasks such as writing a check or calling a friend to arrange a meeting. Performancebased measures, unlike other assessments, do not require participants to be accurate with their self-report and are far more cost efficient and practical than in vivo observations. They also do not require the assessor to wait for the spontaneous performance, thus the behavior of interest can be reliably assessed without a great time-cost for the examiner. Finally, these measures allow for the assessment of an individual's capabilities, rather than simply waiting to measure what the individual does. These measures are gaining widespread acceptance in the research literature (see reference \#30 for a review of several performance-based measures), but at present they are rarely used in clinical practice.

Performance-based measures of functioning for individuals with schizophrenia are available to assess most of the domains of disability in this population (see Table 1 for a summary of several promising performance-based measures). For example, The UCSD Performance-Based Skills Assessment (UPSA; 31 ) is an office-based test measuring the competence of individuals with schizophrenia at performing day-to-day tasks in five domains: household chores, communication, finance, transportation, and planning recreational activities. It has been found to have excellent reliability and test-retest reliability, and to be highly sensitive to the difference between both individuals with schizophrenia and controls (31). The Social Skills Performance Assessment (SSPA; 12), on the other hand, is a performance-based test designed to measure the social competence of individuals with schizophrenia. It consists of two role-played scenes: one scene in which the subject is asked to greet a new neighbor (the interviewer) and one scene in which the subject telephones his landlord (the interviewer) about a leak. Participants are rated in eight categories, including interest/disinterest, fluency, clarity, focus, affect, grooming, and negotiation ability. The SSPA successfully distinguishes between patients and 
normal controls and has been found to have excellent interrater reliability and good test-retest reliability. Scores have been shown to correlate with negative symptoms, cognitive deficits, and health-related quality of well being, but not with positive symptoms or degree of depression (12). There are also measures of vocational competence, such as COMPASS Lite (Valpar International Corporation), a shortened version of Valpar's Computerized Assessment (COMPASS) module. which may require other opportunities, motivations, or skill sets. Unfortunately, there are a host of variables that intervene between competence and performance, such as depression, motivation, anxiety, fear of losing disability payments, and discrimination, to name a few. Improving an individual's competence is a necessary first step in reducing disability, but it may not be sufficient in changing performance in most or all cases. Thus, treatments aimed at reducing disability

\begin{abstract}
This measure is a
computer-based, criterion-refer-
\end{abstract} enced assessment instrument that measures vocational skills as they relate to jobs and training programs, using the rating system of the $R e$ vised Handbook for Analyzing Jobs and the Dictionary of Occupational Titles. Output includes both the number and complexity of jobs for which the individual is currently qualified.

Thus, performance-based assessments have the flexibility to reliably and validly measure an individual's

\begin{tabular}{c} 
Table 1 Overview \\
in Schizoph \\
\hline Measure \\
\hline $\begin{array}{c}\text { Bay Area Functional } \\
\text { Performance Evaluation } \\
\text { (BaFPE) }\end{array}$ \\
Direct Assessment of \\
Functional Status (DAFS) \\
Test of Adaptive Behavior \\
in Schizophrenia (TABS) \\
UCSD Performance-Based \\
Skills Assessment (UPSA) \\
Maryland Assessment of \\
Social Competence (MASC) \\
Social Skills Performance \\
Assessment (SSPA) \\
COMPASS
\end{tabular}

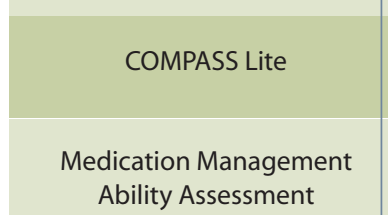

\title{
Measur
}

\section{Domain}

Everyday

living

Everyday
living

Everyday

living

Everyday

living

Social

competence

Social competence

Vocational aptitude

Vocational aptitude

Self-care
Assessing Areas of Disability

(

Author

$+1$

Time to Administer

Williams \&
Bloomer (1987) Lowenstein et al.

(1989) (in press)

Patterson et al.
(2001)

Bellack et al.
(1994)

\section{Patterson et al.} (2001)

Valpar International
Corporation
Valpar International
Corporation
Patterson et al.
(2001)

Time to Administer

$\mathrm{n} / \mathrm{a}$

25
Note: time to administer is in minutes; $\mathrm{n} / \mathrm{a}=$ not available

competence without many of the drawbacks associated with other methods for assessing aspects of disability. In addition, these measures are available to assess functioning across a range of areas that are commonly associated with disability in schizophrenia.

\section{The Distinction between Competence and Performance}

A major issue in the interpretation of functional disability in schizophrenia is that factors other than ability or competence (what one can do) can have an impact on real-world performance (what one does). Treatments aimed at reducing disability generally target an individual's competence, for example, by teaching individuals with schizophrenia social skills or job skills. However, they are aimed at real-world performance, such as making a friend or obtaining a job,

\section{Non-Competence Factors Affecting Performance}

There are several factors that could potentially impact performance of tasks related to disability beyond an individual's ability to engage in those activities. For example, cognitive symptoms appear to be among the best predictors of social competence and community functioning (13). In particular, verbal memory ability appears to be closely related to community functioning (28), as are attention, speed, verbal learning, and executive functioning (32). However, directly relevant to this point is the recent finding by Rosenheck et al. (13) indicating that while cognitive performance was correlated with occupational status in people with schizophrenia, racial and disability status, which are not realistic treatment targets, have a much larger impact. In fact, although there appears to be a clear relationship between cognitive impair- 
ment and real-world disability, some abilities share only $10 \%$ of the variance in everyday outcomes (28).

Thus, disability is influenced by a host of other factors, some more amenable to change than others. Individuals with schizophrenia, as noted above, rarely achieve milestones such as obtaining a job or marrying. Thus, they frequently have low expectations for success. In addition, individuals with schizophrenia frequently experience depressive episodes (33). In fact, it has been estimated that as many as $75 \%$ of individuals with schizophrenia experience symptoms of depression (33). Depressive symptoms, which have been found to occur in individuals with schizophrenia across the lifespan at first episode (34) and in late life (35), may also perpetuate disability within this population. McGurk et al. (36) recently found that individuals with schizophrenia treated in a program that combined supportive employment and cognitive rehabilitation worked more hours for better wages, and also demonstrated lower scores on measures of depression and autistic preoccupation. Thus, having success in treatment and in the real world appears to have a beneficial impact on both an individual's expectations and his or her quality of life. Unfortunately, obtaining the first experience of success is not an easily obtainable goal for individuals with schizophrenia.

In addition, individuals with schizophrenia demonstrate a wide array of cognitive impairments (28) which impacts their ability to successfully deploy skills in real world settings. They also demonstrate a focal impairment in their ability to self-monitor, often referred to as "meta-cognition" $(37,38)$, making it difficult to self-monitor and adjust behavior as needed in both social and occupational settings. Additionally, individuals with schizophrenia may not be able to accurately assess whether tasks will be challenging and, therefore, will require assistance.

Finally, the maintenance of disability in schizophrenia is also affected by practical considerations, such as concerns over losing disability income or medical benefits. Rosenheck et al. (13) found that individuals who received disability payments were less likely to be competitively employed than those who did not. Individuals with schizophrenia who work rarely make enough money to support themselves (39); however, earning enough money to lose disability and medical benefits may be a very real concern (13).

\section{Suggestions for Clinicians}

Functional disability is clearly an important aspect of the schizophrenia disease process. However, standard clinical care for individuals with schizophrenia typically focuses on reducing symptoms of psychosis rather than understanding and treating disability. We, therefore, believe that assessing an individual's disability status should be an integral aspect of treatment. As noted above, current treatments very effectively target the psychotic symptoms of schizophrenia, symptoms that are clearly disruptive and unwanted. Unfortunately, though, effective treatment of psychosis rarely translates into disability reduction. Numerous studies (for a recent review, see reference \#32) have demonstrated that the cross-sectional severity of positive symptoms is a poor predictor of functional outcome. Thus, although pharmacological interventions have often succeeded in treating the positive symptoms of schizophrenia (4), there has been a failure to translate symptom reduction into improved work and social functioning $(28,40,41)$. It is important to keep in mind that for individuals with schizophrenia reduction of symptoms is vastly different from illness recovery.

We also believe that obtaining adequate data is crucial to successfully treating disability within this population. While we acknowledge that it is important to obtain information about patients' performance from patients themselves, as well as from caregivers, we caution that one cannot assume that the information is correct. Biases inherent in self-report and in caregiver ratings should always be kept in mind. For instance, patients with schizophrenia appear to show "depressive realism," in that patients with more severe depression (although still not to the extent of meeting diagnostic criteria for major depression) were actually more accurate at self-evaluation than those with less depression (27). This data suggests that accuracy of self-report might vary over time, changing along with the severity of concurrent depression. However, related to this issue is the finding that more severe depression is associated with relatively poorer real-world outcomes than would be expected from scores on competence measures (27). Thus, depression may increase accuracy of self-evaluation but suppress the likelihood that patients actually live up to their potential.

In addition, we believe that it is just as important to understand an individual's competence as it is to understand his or her real-world performance. Performance under optimal conditions is the limiting factor for real-world outcomes. Improved competence is a necessary part of improving performance, and examining progress in competence throughout treatment is, therefore, an important part of evaluating its effectiveness. Furthermore, numerous factors intervene between competence and performance. If one has a valid assessment of an individual's competence, this can be used to examine barriers to real-world performance of these skills.

Finally, it is crucial to eliminate extraneous barriers to disability reduction whenever possible. Although some factors that relate to the maintenance of disability may not be appropriate treatment targets, several factors are. In addition to pharmacological treatment of psychosis, therefore, we propose that clinicians carefully attend to secondary illnesses such as depressive symptomatology and anxiety. The widespread success of supportive employment programs in 
conjunction with skills training programs for individuals with schizophrenia $(16,35)$ suggests that disability reduction is possible with the proper support and when factors such as poor expectations and problems with self-monitoring are addressed. Thus, psychosocial treatments targeting self-esteem and expectations, as well as residual effects from prior discrimination and stigmatization, could help reduce many barriers to disability reduction beyond an individual's competence.

\section{Conclusions}

Individuals with schizophrenia experience significant disability across a wide range of arenas, including social competence, vocational achievement, everyday living skills, and self-care. This disability, which is responsible for great cost to patients, caregivers, and society, appears to be a core feature of schizophrenia as it is pervasive across domains of functioning and across individual patients. We believe that performance-based measures of functioning are the most appropriate means of assessing disability in clinical settings as they provide vital information about an individual's skill competence. As several factors intervene between competence and performance, understanding an individual's competence allows for a more accurate understanding of barriers to disability reduction and can aid in more effective treatment planning. Assessing functional disability in the schizophrenia population is vital for providing appropriate care with functional recovery, rather than symptom remission, as its goal.

\section{Acknowledgments}

This research was supported by NIMH Grant Number MH 63116 to Dr. Harvey, the Mt. Sinai Silvio Conte Neuroscience Center (NIMH MH 36692; KL Davis PI), and the VA VISN3 MIRECC.

\section{References}

1. Rice DP. Economic burden of mental disorders in the United States. The Economics of Neuroscience 1999;1:40-44.

2. Wu EQ, Birnbaum HG, Shi L, Ball DE, Kessler RC, Moulis M, et al. The economic burden of schizophrenia in the United States in 2002. J Clin Psychiatry 2005;66:1122-1129.

3. Mueser KT, McGurk SR. Schizophrenia. Lancet 2004;363:20632072.

4. Marder SR, Meibach RC. Risperidone in the treatment of schizophrenia. Am J Psychiatry 2004;151:825-835.

5. Hegarty JD, Baldessarini RJ, Tohen M, Waternaux C, Oepen G. One hundred years of schizophrenia: a meta-analysis of the outcome literature. Am J Psychiatry 1994;151:1409-1416.

6. Kendler KS, McGuire M, Gruenberg AM, Walsh D. Outcome and family study of the subtypes of schizophrenia in the west of Ireland. Am J Psychiatry 1994;151:849-856.

7. Couture SM, Penn DL, Roberts DL. The functional significance of social cognition in schizophrenia: a review. Schizophr Bull 2006;32(Suppl 1):S44-63.

8. Morrison RL, Bellack AS. Social functioning in schizophrenia patients: clinical and research issues. Schizophr Bull 1987;13:715-725.

9. Horan WP, Subotnik KL, Snyder KS, Nuechterlein KH. Do recent-onset schizophrenia patients experience a "social network crisis?" Psychiatry 2006;69:115-129.

10. Sharma T, Antonova L. Cognitive function in schizophrenia. Deficits, functional consequences, and future treatment. Psychiatr Clin North Am 2003;26:25-40.

11. Harvey PD, Velligan DI, Bellack AS. Performance-based measures of functional skill: Usefulness in clinical treatment studies. Schizophr Bull 2007 May 9; Epub ahead of print.

12. Patterson TL, Moscona S, McKibbin CL, Davidson K, Jeste DV. Social skills performance assessment among older patients with schizophrenia. Schizophr Res 2001; 48:351-360.

13. Rosenheck R, Leslie D, Keefe R, McEvoy J, Swartz M, Perkins D, et al; CATIE Study Investigators Group. Barriers to employment for people with schizophrenia. Am J Psychiatry 2006;163:411-417.

14. Mueser KT, Salyers MP, Mueser PR. A prospective analysis of work in schizophrenia. Schizophr Bull 2001;27:281-296.

15. Bond GR. Supported employment: evidence for an evidencebased practice. Psychiatr Rehabil J 2004;27:345-359.

16. Bell MD, Bryson GJ, Greig TC, Fiszdon JM, Wexler BE. Neurocognitive enhancement therapy with work therapy: Productivity outcomes at 6- and 12-month follow-ups. J Rehabil Res Dev 2005;42:829-838.

17. Dickerson FB, Ringel NB, Parente F. Subjective quality of life in out-patients with schizophrenia: clinical and utilization correlates. Acta Psychiatr Scand 1998;98:124-127.

18. Jaeger J, Berns SM, Czobor P. The multidimensional scale of independent functioning: a new instrument for measuring functional disability in psychiatric populations. Schizophr Bull 2003;29:153-168.

19. Velligan DI, Mahurin RK, Diamond PL, Hazleton BC, Eckert SL, Miller AL. The functional significance of symptomatology and cognitive function in schizophrenia. Schizophr Res 1997;25:21-31.

20. Velligan DM, Bow-Thomas CC, Huntzinger C, Ritch J, Ledbetter N, Prihoda TJ, et al. A randomized controlled trial of the use of compensatory strategies to enhance adaptive functioning for outpatients with schizophrenia. Am J Psychiatry 2000;157:1317-1323.

21. Alptekin K, Erkoc S, Gogus AK, Kultur S, Mete L, Ucok A, Yazici KM. Disability in schizophrenia: clinical correlates and prediction over 1-year follow-up. Psychiatry Res 2005; 135:103-111.

22. Fenton WS, Blyler CR, Heinssen RK. Determinants of medication compliance in schizophrenia: empirical and clinical 
findings. Schizophr Bull 1997;23:637-651.

23. McCarthy JF, Piette JD, Fortney JC, Valenstein M, Blow FC. Outpatient visit chaining among patients with serious mental illness. Med Care 2006;44:257-264.

24. Di Michele V, Bolino F, Mazza M, Roncone R, Casacchia M. Relapsing versus non relapsing course of schizophrenia: a cohort study in a community based mental health service. Epidemiol Psichiatr Soc 2007;16:50-58.

25. Amador XF, Strauss DH, Yale SA, Flaum MM, Endicott J, Gorman JM. Assessment of insight in psychosis. Am J Psychiatry $1993 ; 150: 873-879$.

26. Keefe RS, Poe M, Walker TM, Kang JW, Harvey PD. The Schizophrenia Cognition Rating Scale: an interview-based assessment and its relationship to cognition, real-world functioning, and functional capacity. Am J Psychiatry 2006; 163:426-432.

27. Bowie CR, Twamley EW, Anderson H, Halpern B, Patterson TL, Harvey PD. Self-assessment of functional status in schizophrenia. J Psychiatr Res 2006 Sep 30; Epub ahead of print.

28. Green MF. What are the functional consequences of neurocognitive deficits in schizophrenia? Am J Psychiatry 1996;153:321-330.

29. Patterson TL, Semple SJ, Shaw WS, Grant I, Jeste DV. Researching the caregiver: family members who care for older psychotic patients. Psychiatr Ann 1996;26:772-784.

30. Moore DJ, Palmer BW, Patterson TL, Jeste DV. A review of performance-based measures of functional living skills. J Psychiatr Res 2007;41:97-118.

31. Patterson TL, Goldman S, McKibbon CL, Hughs T, Jeste DV. UCSD Performance-Based Skills Assessment: development of a new measure of everyday functioning for severely mentally ill adults. Schizophr Bull 2001;27:235-245.

32. McGurk SR, Meuser KT. Cognitive functioning, symptoms, and work in supported employment: a review and heuristic model. Schizophr Res 2004;70:147-173.

33. Siris SG. Depression in schizophrenia: perspective in the era of "atypical" antipsychotic agents. Am J Psychiatry 2001;158:1379-1389.

34. Emsley RA, Oosthuizen PP, Joubert AF, Roberts MC, Stein DJ. Depressive and anxiety symptoms in patients with schizophrenia and schizophreniform disorder. J Clin Psychiatry 1999;60:747-751.

35. Zisook S, Nyer M, Kasckow J, Golshan S, Lehman D, Montross L. Depressive symptom patterns in patients with chronic schizophrenia and subsyndromal depression. Schizophr Res 2006;86:226-233.

36. McGurk SR, Mueser KT, Feldman K, Wolfe R, Pascaris A. Cognitive training for supported employment: 2-3 year outcomes of a randomized controlled trial. Am J Psychiatry 2007;164:437-441.

37. Koren D, Seidman LJ, Poyurovsky M, Goldsmith M, Viksman P, Zichel S, et al. The neuropsychological basis of insight in first-episode schizophrenia: a pilot metacognitive study. Schizophr Res 2004;70:195-202.

38. Koren D, Poyurovsky M, Seidman LJ, Goldsmith M, Wenger $\mathrm{S}$, Klein EM. The neuropsychological basis of competence to consent in first-episode schizophrenia: a pilot metacognitive study. Biol Psychiatry 2005;57:609-616.

39. Becker D, Drake RE. A working life. New York: Oxford University Press; 2001.

40. McGurk SR, Meuser KT, Harvey PD, LaPuglia R, Marder J. Cognitive and symptom predictors of work outcomes for clients with schizophrenia in supported employment. Psychiatr Serv 2003;54:1129-1135.

41. Green MF, Kern RS, Braff DL, Mintz J. Neurocognitive deficits and functional outcome in schizophrenia: are we measuring the "right stuff?" Schizophr Bull 2000;26:119-136. 